\title{
Changes in protein patterns of Staphylococcus aureus and Escherichia coli by silver nanoparticles capped with poly (4-styrenesulfonic acid-co-maleic acid) polymer
}

\author{
Hathaichanok Tamiyakul', Sittiruk Roytrakul2, Janthima Jaresitthikunchai², Narumon Phaonakrop², \\ Somboon Tanasupawat ${ }^{3}$, Warangkana Warisnoicharoen ${ }^{4, *}$
}

\begin{abstract}
Background: While silver nanoparticles (AgNPs) are increasingly attractive as an antibacterial agent in many applications, the effect of AgNPs on bacterial protein profiles, especially AgNPs stabilized by polymeric molecules, is not well understood.

Objectives: To investigate the changes in bacterial protein patterns by AgNPs capped with poly (4-styrenesulfonic acid-co-maleic acid) (AgNPs-PSSMA) polymer toward Staphylococcus aureus ATCC 25923 and Escherichia coli ATCC 25922.

Methods: The growth of bacteria after incubated with AgNPs-PSSMA for different time intervals was determined by optical density at $600 \mathrm{~nm}$. Their protein patterns were observed using sodium dodecyl sulfate polyacrylamide gel electrophoresis (SDS-PAGE), and the proteomic analysis of extracted proteins was determined by liquid chromatography-tandem mass spectrometry (LC-MS/MS).

Results: AgNPs-PSSMA was able to inhibit the growth of both S. aureus and E. coli cells. The treated bacterial cells expressed more proteins than the untreated cells as seen from SDS-PAGE study. Nanosilver (NS) caused the upregulation of metabolic gene, waaA, in $S$. aureus cells. For E. coli cells, the upregulated proteins were metabolic genes (srlB, fliE, murD) and other genes dealt with DNA replication (dinG), DNA-RNA transcription (yrdD), RNAprotein translation (rplD), molecular transport (sapF), and signal transduction (tdcF).

Conclusions: The antibacterial effect of AgNPs-PSSMA may arise by changing the bacterial proteins and thus interfering with the normal cell function.
\end{abstract}

Keywords: Escherichia coli; nanoparticles; nanomedicine; proteomics; Staphylococcus aureus

*Correspondence to: Warangkana Warisnoicharoen, Department of Food and Pharmaceutical Chemistry, Faculty of Pharmaceutical Sciences, Chulalongkorn University, Bangkok 10330, Thailand, e-mail: warangkana.w@chula.ac.th 'Graduate School of Nanoscience and Technology, Chulalongkorn University, Bangkok 10330, Thailand 2Proteomics Research Laboratory, National Center for Genetic Engineering and Biotechnology (BIOTEC), The National Science and Technology Development Agency (NSTDA), Pathum Thani 12120, Thailand

${ }^{3}$ Department of Biochemistry and Microbiology, Faculty of Pharmaceutical Sciences, Chulalongkorn University, Bangkok 10330, Thailand ${ }^{4}$ Department of Food and Pharmaceutical Chemistry, Faculty of Pharmaceutical Sciences, Chulalongkorn University, Bangkok 10330, Thailand 
The high surface area per mass and small size of the nanoparticles make silver nanoparticles (AgNPs) an effective antibacterial agent [1-3]. For this reason, AgNPs have been applied in diverse medical applications ranging from silverbased dressings to silver-coated medicinal devices and on numerous consumer products [4]. Although AgNPs have been widely used for antimicrobials, their mechanism is still not well understood. Possible antimicrobial mechanisms proposed include (1) interference with cell wall synthesis [5-8], (2) inhibition of protein synthesis $[6,8]$, (3) interference with nucleic acid synthesis $[6,8]$, and (4) inhibition of a metabolic pathway $[6,8,9]$. To get a better insight on how AgNPs affect bacterial growth, the proteomic approach is concerned as an effective tool for protein analysis. Recently, only few studies have been reported on bacterial proteomes after AgNP exposure [10-17], and most of the AgNPs previously described were stabilized with anionic citrate.

It is noteworthy that the stability of AgNPs synthesized can be increased by coating the nanoparticles with polymers, which can prevent particle agglomeration by steric hindrance. The differences in type of stabilizers could lead to different properties of AgNPs including the release or distribution of silver ions related to perhaps the protein activity $[11,12]$. Thus, to study of how AgNPs affect the protein function, the capping agent of synthesized AgNPs should be mentioned. Poly (4-styrenesulfonic acid-co-maleic acid) or PSSMA is a polyelectrolyte copolymer of styrenesulfonic acid and maleic acid, which is widely used to develop multilayer thin films for biomaterial or controlled drug release [18].

In this paper, AgNPs capped with anionic polystyrene$o$-maleic acid polymer (AgNPs-PSSMA) were studied for antibacterial activity against Gram-positive bacteria, Staphylococcus aureus ATCC 25923, and Gram-negative bacteria, Escherichia coli ATCC 25922. Bacterial proteins were identified by proteomic approach. Our study is the first report on changes in protein expression of bacteria after the antibacterial (AgNPs-PSSMA) treatment.

\section{Materials and methods}

\section{Preparation and characterization of AgNPs}

Nanoscale silver particles $(3.33 \mathrm{mM})$ stabilized by PSSMA (Aldrich, USA) were prepared using a chemical reduction and characterized as detailed in Tamiyakul et al. [19]. Briefly, $10 \mathrm{mM}$ sodium borohydride $\left(\mathrm{NaBH}_{4}\right.$; Fisher Scientific, USA) was rapidly added into a mixture of $10 \mathrm{mM}$ silver nitrate $\left(\mathrm{AgNO}_{3}\right.$; Carlo Erba Reagents, Italy) and $1 \mathrm{mM}$ PSSMA in order to reduce silver ions to form nanoparticles. A dark brown solution of PSSMA-stabilized nanosilver (NS) showed a characteristic peak at a maximum wavelength $\left(\lambda_{\max }\right)$ of $395 \mathrm{~nm}$, as determined by Specord S 100 UV spectrophotometer (Analytikjena, Germany). The spherical shape of NS was seen from transmission electron microscope (TEM; JEM-2100, Jeol, Japan). The average paricle size of $5.21 \pm 4.43 \mathrm{~nm}(\mathrm{n}=250)$ was obtained by further TEM analysis using equipped SemAfore v.5.21 program. The value of surface charge of NS measured by Zetasizer NanoZS (Malvern Instruments, UK) was $-35.5 \pm 0.96 \mathrm{mV}$.

\section{Bacteria, culture media, and cultivation}

The strains of Gram-positive S. aureus ATCC 25923 and Gram-negative E. coli ATCC 25922 were purchased from American Type Culture Collection (ATCC). Tryptic soy broth (TSB; Difco, USA) and tryptic soy agar (TSA; Difco, USA) media were used for bacterial cultivation at $37^{\circ} \mathrm{C}$. To prepare bacteria for investigation of bacterial growth, a loop of $S$. aureus and E. coli in glycerol stock was streaked on TSA agar plate and then incubated at $37^{\circ} \mathrm{C}$ for $24 \mathrm{~h}$. Then, a bacterial colony was inoculated into $10 \mathrm{~mL}$ TSB broth and further incubated at $37^{\circ} \mathrm{C}$ for $24 \mathrm{~h}$. The bacteria were then centrifuged at $5000 \mathrm{rpm}$ for $3 \mathrm{~min}$. The supernatant was discarded, and the pellet was re-suspended with TSB media for further study. For the TSB media, it was prepared by dissolving $30 \mathrm{~g}$ TSB powder in $1 \mathrm{~L}$ water or NS and then sterilized by membrane filtration, Acrodisc syringe filter with $0.2 \mu \mathrm{m}$ Supor membrane (Pall Science, USA).

\section{Growth of bacteria exposed to AgNPs}

The bacterial growth experiment was performed using S. aureus and E. coli $\left(1.5 \times 10^{8} \mathrm{CFU} / \mathrm{mL}\right.$, determined at OD of 0.1 at $600-\mathrm{nm}$ wavelength $\left(\mathrm{OD}_{600}\right)$. Bacteria incubated either in an absence (control) or in a presence of NS were collected at different incubation times $(0-5 \mathrm{~h})$. The bacterial growth curves were determined in quadruplicate from $\mathrm{OD}_{600}$ values.

\section{Bacterial protein extraction}

Bacteria collected at incubation times of $1,15,30,45,60,120$, and $180 \mathrm{~min}$ were centrifuged at $5000 \mathrm{rpm}$ for $5 \mathrm{~min}$, and the supernatant was discarded. The pellet was re-suspended with $0.5 \% \mathrm{w} / \mathrm{v}$ sodium dodecyl sulfate (SDS; Sigma-Aldrich, USA) solution, vortexed vigorously, and frozen in a freezer at $-80^{\circ} \mathrm{C}$ 
overnight. After thawing, the suspension was centrifuged at $5000 \mathrm{rpm}$ for $5 \mathrm{~min}$ at room temperature, and the supernatant was determined for the extracted protein by a method of Lowry using bovine serum albumin (BSA) as a standard [20].

\section{Sodium dodecyl sulfate polyacrylamide gel electrophoresis}

The extracted proteins were mixed with a loading buffer (0.125 M Tris- $\mathrm{HCl} \mathrm{pH} 6.8,20 \% \mathrm{w} / \mathrm{v}$ glycerol, 5\% w/v SDS, $0.2 \mathrm{M}$ dithiothreitol [DTT], $0.02 \% \mathrm{w} / \mathrm{v}$ bromophenol blue) before loading onto polyacrylamide gels $(12.5 \%$ separating gel, 5\% stacking gel), which were prepared following the method of Laemmli [21]. An electrophoresis system was run at $50 \mathrm{~V}$ for stacking gel and $70 \mathrm{~V}$ for separating gel until the dye front reached approximately $1 \mathrm{~cm}$ from the edge of the gel. All gels were visualized by silver and Coomassie brilliant blue $\mathrm{G}$ staining and scanned with Image Scanner (Bio-Rad, USA).

\section{Liquid chromatography-tandem mass spectrometry}

In order to analyze the bacterial peptides by liquid chromatography-tandem mass spectrometry (LC-MS/MS), each lane of the gel was sectioned horizontally in order to acquire the entire population of proteins in the lane. Gel slices were excised to obtain gel plug with $1 \mathrm{~mm}^{3}$ in size. For in-gel digestion, the gel plugs were dehydrated with $100 \%$ acetonitrile (RCI Labscan, Thailand) and reduced with $10 \mathrm{mM}$ DTT (USB Co. Ltd., USA) for $1 \mathrm{~h}$ at room temperature. Alkylation was further done in the dark using $100 \mathrm{mM}$ iodoacetamide (GE Healthcare, UK) for $1 \mathrm{~h}$ at room temperature before dehydrated twice with $100 \%$ acetonitrile for $5 \mathrm{~min}$. Finally, $10 \mathrm{ng}$ of trypsin solution (Promega, USA) was added to the gels followed by overnight incubation at $37^{\circ} \mathrm{C}$ so as to digest proteins. Peptides were extracted, collected, and kept at $-80^{\circ} \mathrm{C}$ prior to mass spectrometry analysis [22].

For the peptide analysis, the extracted peptides were re-suspended with $0.1 \% \mathrm{v} / \mathrm{v}$ formic acid (FA, [AppliChem, Germany]) and centrifuged at 10,000 rpm for $5 \mathrm{~min}$. The supernatant was injected into Ultimate 3000 LC system (Dionex) coupled with ESI-ion Trap MS (HCT Ultra PTM Discovery System, BrukerDaltonics Ltd., UK). DeCyder MS Differential Analysis software (DeCyderMS, GE Healthcare) was used for protein quantitation [23, 24]. Mascot software (Matrix Science Ltd., London, UK) was used for the protein identification based on the National Center for Biotechnology Information (NCBI) database (http://www.ncbi.nlm.nih.gov) [25].
For Mascot MS/MS ion search, the peptide taxonomy was set up as bacteria (eubacteria), fixed modifications as carbamidomethyl (C), and variable modifications as oxidation (M). The peptide charge was $1+, 2+$, and $3+$ with MS/MS ion mass tolerance of $\pm 1.2 \mathrm{Da}$, fragment mass tolerance of $\pm 0.6 \mathrm{Da}$, and allowance for one miscleavage [26]. The protein functions of the identified proteins were further searched based on the UniProt (http://www.uniprot.org) for enabling the gene ontology (GO) prediction. The association or interaction network of protein was clarified through the Search Tool for the Retrieval of Interacting Genes/Proteins or String database (http://string-db.org). The String database analyzes the data based on the known and predicted protein interactions [27].

\section{Results}

\section{Bacterial growth and extracted protein from gel electrophoresis}

The proliferation of E. coli cells and $S$. aureus cells after exposed to AgNPs-PSSMA was determined by measuring $\mathrm{OD}_{600}$ at various incubation times. The bacterial proteins of E. coli and $S$. aureus cells treated with NS for incubation times of $15,30,45,60,120$, and 180 min were determined by double staining SDS-polyacrylamide gel electrophoresis (PAGE). The results indicated that growths of the bacteria were inhibited, and no exponential phase was clearly observed in the NS-treated bacteria (Figure 1A,B). In contrary, for the untreated (control) bacterial cells, the growth pattern was in a lag phase for $1 \mathrm{~h}$ and then continued to an exponential phase. From the SDS-PAGE study, NS-treated S. aureus and E.coli cells showed more protein expression than the corresponding untreated cells (Figure 1C,D).

In order to maintain the optimal level of bacterial protein prior to proteomic analysis, the cells cultured in the medium were collected at time intervals covering the early exponential phase, which were $15,30,45,60,120$, and $180 \mathrm{~min}$.

\section{Bacterial proteomic analysis}

The extracted proteins of bacteria gathered from every incubation time were digested prior to analysis by LC/MS-MS. The proteins of NS-treated $E$. coli cells, untreated $E$. coli cells, NStreated $S$. aureus cells, and untreated $S$. aureus cells were identified based on the NCBI database. There were a total number of 860 bacterial proteins matched with proteins deposited in the database. However, 26 proteins belonged to E. coli (treated 
A

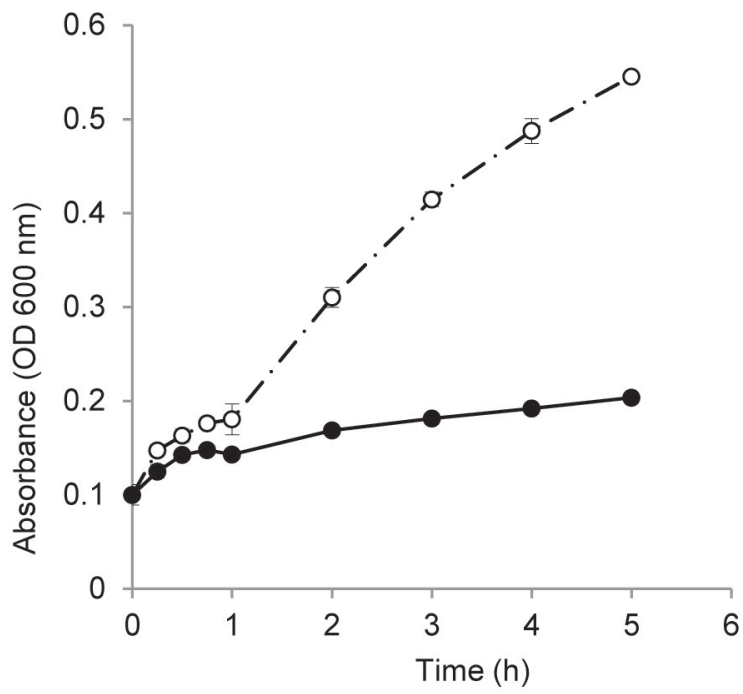

B

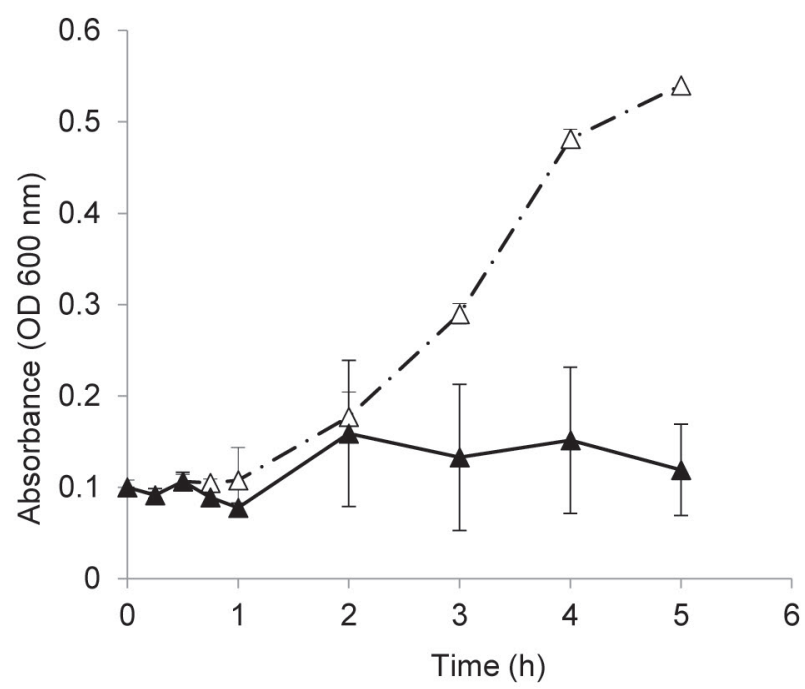

D

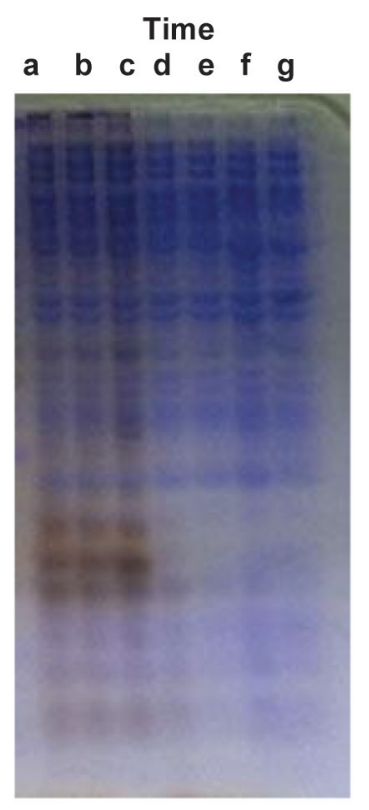

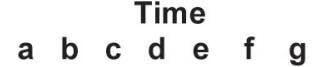

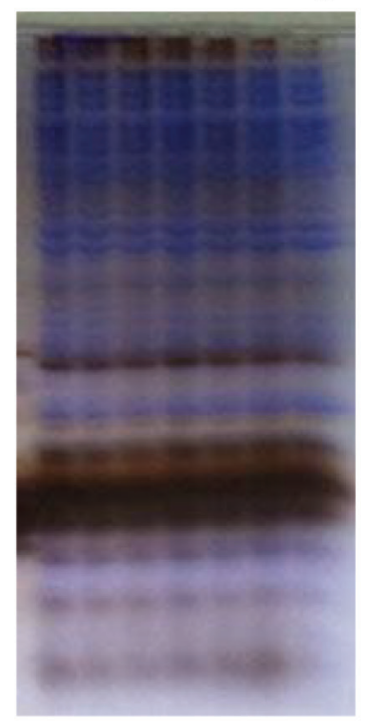

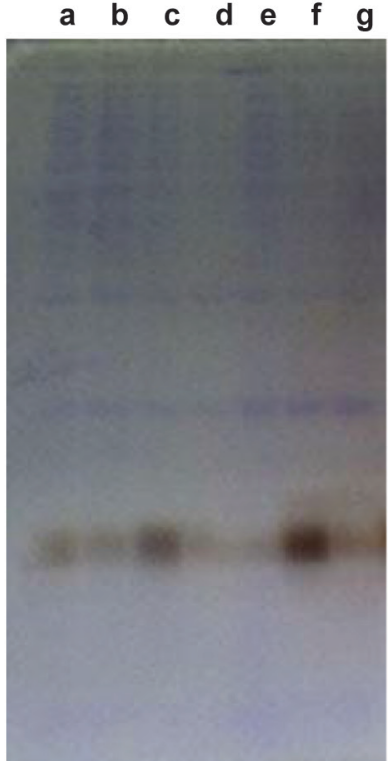

a b c dime e f $g$

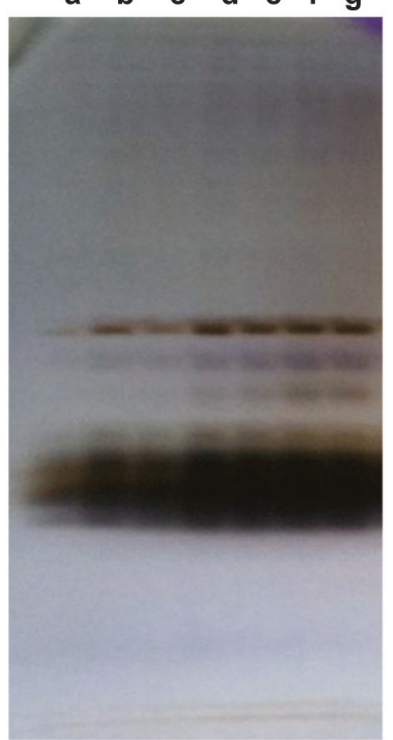

Figure 1. (A) Growth curves of Staphylococcus aureus ATCC 25923 cells and (B) those of Escherichia coli ATCC 25922 cells after exposed (solid line) and unexposed (dashed line) to nanosilver. Error bars indicate standard deviations of the means of $n=4$. (C) Patterns of total protein extracted from S. aureus ATCC 25923 and (D) those of E. coli ATCC 25922 after (left) unexposed and (right) exposed to nanosilver at different incubation times (a: 0 min, b: $15 \mathrm{~min}, \mathrm{c:} 30 \mathrm{~min}$, d: $45 \mathrm{~min}$, e: $60 \mathrm{~min}, \mathrm{f:} 120 \mathrm{~min}$, and g: $180 \mathrm{~min}$ ).

or untreated) and 3 proteins belonged to $S$. aureus (treated or untreated) were further identified for protein functions as shown in Table 1.

From proteomes analysis, AgNPs-PSSMA were able to downregulate long-chain fatty acid transport protein (fadL) of S. aureus and quinolinate synthase A (nadA) and protein YhgF (yhgF) of E. coli. For S. aureus, only 3-deoxy-D-manno-octulosonic-acid transferase protein (waaA) was upregulated after exposed to NS (Table 1). In contrast, eight proteins of E. coli were expressed after exposed to NS. The E. coli proteins mentioned were functioned with metabolism (srlB, fliE, murD), DNA replication (dinG), DNA-RNA transcription (yrdD), RNA-protein translation (rplD), molecular transport (sapF), and signal transduction (tdcF).

The upregulated genes and downregulated genes of the bacteria were further studied for protein-protein interaction data via String database. The bioinformatics result was shown as a network of predicted functional associations for 
Table 1. The identified proteins by LC-MS/MS with known functions of Staphylococcus aureus and Escherichia coli with untreated (control) and nanosilver (NS)-treated conditions

\begin{tabular}{|c|c|c|c|}
\hline $\begin{array}{l}\text { Protein accession } \\
\text { number }\end{array}$ & Protein name & $\begin{array}{l}\text { Protein } \\
\text { symbol }\end{array}$ & Function \\
\hline \multicolumn{4}{|l|}{ S. aureus (control) } \\
\hline gi|170081960 & Long-chain fatty acid transport protein & fadL & Molecular transport \\
\hline \multicolumn{4}{|c|}{ S. aureus (NS treated) } \\
\hline gi|326798469 & 3-Deoxy-D-manno-octulosonic-acid transferase & waaA & Metabolic process \\
\hline \multicolumn{4}{|c|}{ S. aureus (control and NS treated) } \\
\hline gi|1786970 & 2,3-Bisphosphoglycerate-dependent phosphoglycerate mutase & gpmA & Metabolic process \\
\hline \multicolumn{4}{|l|}{ E. coli (control) } \\
\hline gi|1786964 & Quinolinate synthase A & nadA & Metabolic process \\
\hline gi|153844091 & Protein YhgF & yhgF & Metabolic process \\
\hline \multicolumn{4}{|l|}{ E. coli (NS treated) } \\
\hline gi|146319043 & Threonine dehydrogenase and related $\mathrm{Zn}$-dependent dehydrogenase & srlB & Metabolic process \\
\hline gi|308050024 & Flagellar hook-basal body protein & flie & Metabolic process \\
\hline gi|156973219 & UDP-N-acetylmuramoyl-L-alanyl-D-glutamate synthetase & murD & Metabolic process \\
\hline gi|1279404 & Peptide transport system ATP-binding protein SapF & sapF & Molecular transport \\
\hline gi|323524861 & Enoyl-CoA hydratase/isomerase & $\operatorname{tdcF}$ & Signal transduction \\
\hline gi|1787018 & Probable ATP-dependent helicase DinG & $\operatorname{din} G$ & DNA replication \\
\hline gi|283778629 & DNA topoisomerase type IA Zn finger domain-containing protein & yrdD & Transcription \\
\hline gi|1789715 & $50 S$ ribosomal protein $\mathrm{L} 4$ & rplD & Translation \\
\hline \multicolumn{4}{|c|}{ E. coli (control and NS treated) } \\
\hline gi|227357988 & Siderophore biosynthesis lucA/lucC family protein & iucA & Metabolic process \\
\hline gi|226943115 & Isopropylmalate isomerase large subunit & leuC & Metabolic process \\
\hline gi|225010785 & PhoH family protein & phoH & Metabolic process \\
\hline gi|261854682 & Phosphoribosylaminoimidazolecarboxamide formyltransferase/IMP cyclohydrolase & purH & Metabolic process \\
\hline gi|319762019 & Haloacid dehalogenase (HAD)-superfamily hydrolase & yqaB & Metabolic process \\
\hline gi|331007050 & Colicin V production protein & cvpA & Molecular transport \\
\hline gi|325067458 & Oligopeptide ATP-biding cassette $(A B C)$ transporter periplasmic protein & oppA & Molecular transport \\
\hline gi|320353100 & OmpA/MotB domain-containing protein & motB & Molecular transport \\
\hline gi|257459944 & Putative TonB-dependent receptor & tonB & Signal transduction \\
\hline gi|333984533 & TonB-dependent siderophore receptor & yncD & Signal transduction \\
\hline gi|312196358 & IcIR family transcriptional regulator & iclR & Transcription \\
\hline gi|384412003 & NusA antitermination factor & nusA & Transcription \\
\hline gi|85860692 & ATP-dependent RNA helicase & rhlB & Transcription \\
\hline gi|260893293 & Alanyl-tRNA synthetase & alas & Translation \\
\hline gi|227495901 & Leucine-tRNA ligase & leus & Translation \\
\hline gi|29653579 & 50 S ribosomal protein $\mathrm{L} 1$ & rplA & Translation \\
\hline
\end{tabular}

a group of proteins. The network nodes represent the proteins while the edges (lines) are the predicted associations of protein (Figure 2). The connection among proteins in $S$. aureus represented genes mainly involved in metabolic process, while those found in E. coli were genes mostly implicated mainly in the transporter system, metabolic activity, transcription, and translation. Interestingly, for E. coli, there were four unmatched proteins, such as family transcriptional regulator (iclR), HAD-superfamily hydrolase (yqaB), threonine dehydrogenase, and related $\mathrm{Zn}$-dependent dehydrogenase (srlB) and probable ATP-dependent helicase DinG (dinG). As srlB and dinG genes were expressed in NS-treated
E. coli, they were represented as biomarkers for antibacterial effect of AgNPs-PSSMA.

\section{Discussion}

In this study, we investigate the role of AgNPs-PSSMA on the changes in protein patterns of Gram-positive $S$. aureus and Gram-negative E. coli, which eventually lead to bacterial cell death. A decrease in the cell survival of the bacteria treated with NS was observed while the untreated control cells grew exponentially after an hour of incubation (Figure 1A,B). From 


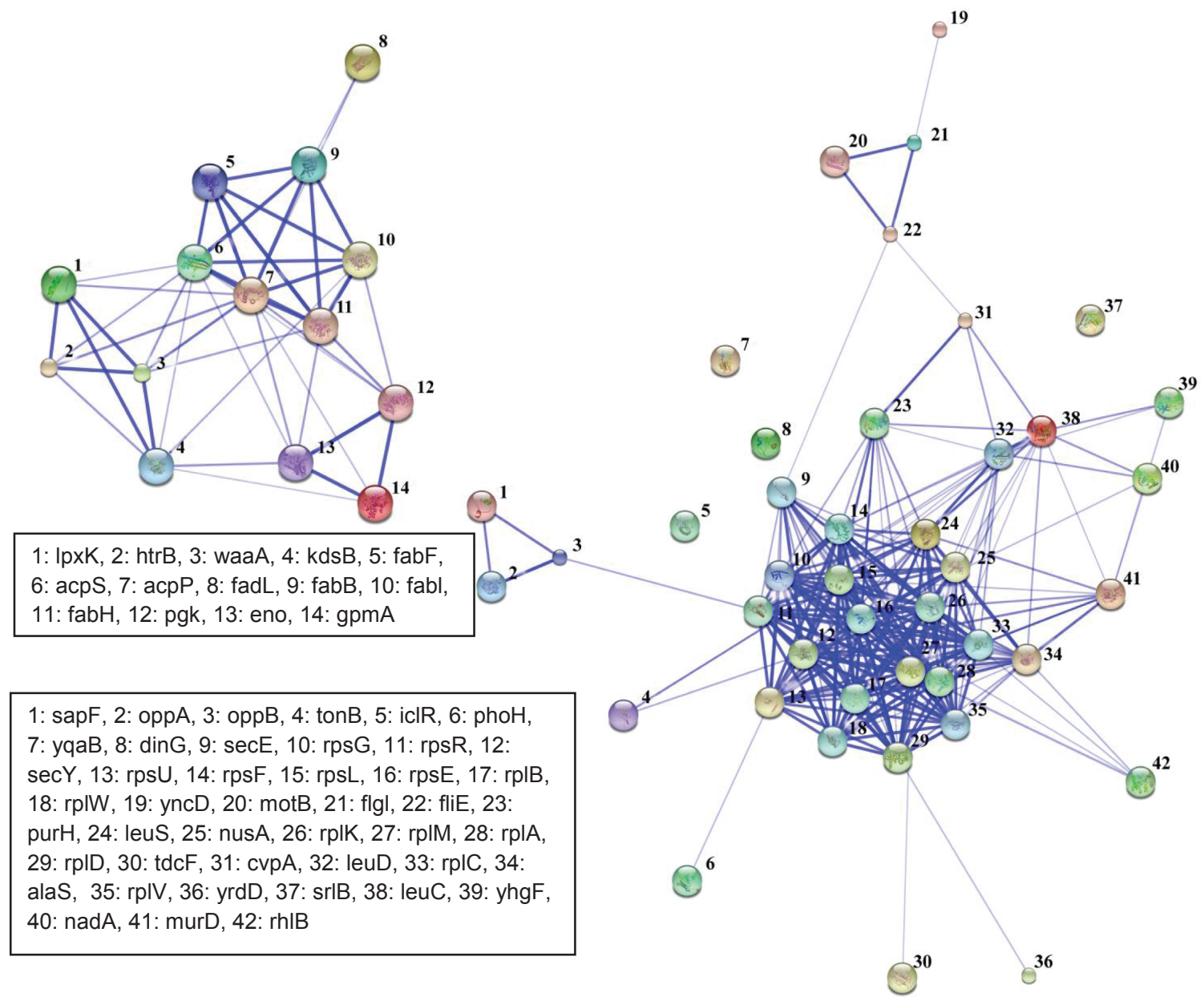

Figure 2. Interaction network of matched categories for (left) Staphylococcus aureus ATCC 25923 and (right) Escherichia coli ATCC 25922. Thicker lines indicate higher confidence and higher number of interactions described by String database.

the previous reports on the antimicrobial activity of NS [28, 29], it is anticipated that AgNPs-PSSMA when penetrating into the cells make cell death by causing structural changes and damage, which could disturb vital cell functions. From our study, the changes in cellular protein after exposed to AgNPs-PSSMA were obviously seen from gel electrophoresis results, especially the E.coli cells (Figure 1C,D). Protein pattern modification leads to bacterial death by interference with metabolic function and synthesis of cell wall, nucleic acid, and protein [6].

We used the proteomic approach as a tool to explore the bacterial proteins of the NS-treated cells. For S. aureus, protein fadL was downregulated by NS. Protein fadL is associated with protein receptor and translocation of long-chain fatty acids across the outer membrane, the first part to confront with NS [30]. AgNPs-PSSMA might affect the protein receptors leading to lipid transport deficiency and ultimately cell death [2, 31, 32]. In contrast, 3-deoxy-D-manno-octulosonic acid (Kdo) transferase or waaA, a protein locating at an inner cell membrane and involved in lipopolysaccharide (LPS) biosynthesis [33, 34], was upregulated in NS-treated S. aureus. Cellular oxidative response has been reported to promote the function of LPS biosynthesis [35], and NS is evident to cause oxidative stress. It was then not unexpected that AgNPsPSSMA induce waaA gene.

For NS-treated E. coli, quinolinate synthase A (nadA) and protein $\mathrm{YhgF}$ (yhgF) were downregulated. Protein nadA is in a cytoplasm involved in the cell metabolism. It catalyzes the condensation of iminoaspartate with dihydroxyacetone phosphate to form quinolinate (pyridine nucleotide biosynthesis) [36-38]. As the appearance of hydrogen peroxide $\left(\mathrm{H}_{2} \mathrm{O}_{2}\right)$ has known to depress quinolinate synthetase, which is used for quinolinate production [39], a release of $\mathrm{H}_{2} \mathrm{O}_{2}$ from NS [40] could possibly lead to inhibition of nadA protein. Protein yhgF 
is the respiratory protein involved in cyclic di-GMP signaling [41]. Accordingly, NS could interfere with the respiratory process of the bacteria, finally leading to cell death.

In contrary to the downregulation, NS triggered the expression of approximately eight proteins in E. coli cells (Table 1). It seems that when $E$. coli cells are perturbed, a higher number of genes dealt with many cell functions are expressed [42]. In this study, the upregulated proteins found were involved in the metabolic function (srlB, fliE, and murD proteins), signal transduction (tdcF protein), and signal transcription ( $\mathrm{yrdD}$ protein).

Interestingly, we have found the upregulation of proteins dinG, rplD, and sapF, which are suggested to play a role in antimicrobial resistance. The ATP-dependent helicase dinG (dinG) is related to DNA repair and replication [43]. The process of DNA repair after exposure to NS might be consequences of cell resistance to antibacterials. Protein rplD is the 50S ribosomal protein functions as ribosome-mediated translation of mRNA into a polypeptide [44]. Protein sapF is an ATP-binding protein in plasma membrane involved in a peptide transport system [45]. The upregulation of proteins $\mathrm{rplD}$ and sapF of $E$. coli perhaps indicates a change in protein synthesis after confront with antibacterial agent.

The previous proteomic study in $E$. coli cells was usually focused on the membrane protein. The expression of outer membrane precursors (OmpA, OmpC, OmpF, OppA) of E. coli cells was reported to be enhanced by NS [10]. The $r f a$ gene necessary for outer member lipopolysaccharide was expressed in E. coli mutant strain [12]. The bacterial response to NS could be different and perhaps dependent on a type of stabilizer. For example, genes functioning in quinone binding and ubiquinone biosynthesis were found in E. coli mutant strain treated with AgNPs stabilized by polyethylene imine polymer but not found in those treated with polyvinylpyrrolidone polymer-capped AgNPs [12]. Herein, we reported the additional information about the effect of AgNPs stabilized by PSSMA polymer on gene expression of $S$. aureus and E. coli cells. Finally, the association of bacterial proteins was determined via String database. We have found that srlB and $\operatorname{din} G$ proteins expressed in E. coli after confronted with NS were not found for any protein association (Figure 2). The finding makes proteins srlB and dinG be considered as novel biomarkers for antibacterial effect of such NS.

\section{Conclusion}

The stable AgNPs-PSSMA could be used as antibacterial agents to Gram-positive and Gram-negative bacteria. NS caused both downregulation and upregulation of proteins in bacterial cells with the latter was more obviously found in E. coli cells.

In this study, the NS without capping agent added was not performed due to the reasons dealing with the stability of AgNPs. The data obtained from the present study were the antibacterial effect AgNPs capped with PSSMA. The AgNPs could be further applied clinically as materials for antibacterial purposes. As the bacterial proteins change after AgNPs exposure seemed to be depend on the type of stabilizers [12], the further study should be on the comparison of bacterial protein change of AgNPs capped with different types of polymer. The information could be used to select the appropriate stabilizing polymer for the targeted bacterial proteins.

Author contributions. SR, ST, and WW contributed substantially to the conception and design of this study. HT, JJ, and NP contributed substantially to the acquisition of data. HT, SR, ST, and WW analyzed and interpreted the data. HT and WW drafted the manuscript. SR, JJ, NP, ST, and WW contributed substantially to its critical revision. All the authors approved the final version submitted for publication and take responsibility for the statements made in the published article.

Acknowledgments. This work was supported by the 90th Anniversary of Chulalongkorn University Fund (Ratchadaphiseksomphot Endowment Fund) and the Ratchadaphiseksomphot Endowment Fund-2013 of Chulalongkorn University (CU-56-650-HR). We thank Proteomics Research Laboratory, National Center for Genetic Engineering and Biotechnology (BIOTEC) for technical assistance in the proteomics approach.

Conflict of interest statement. The authors have completed and submitted the International Committee of Medical Journal Editors Uniform Disclosure Form for Potential Conflicts of Interest. None of the authors disclose any conflicts of interest.

\section{References}

[1] Gong P, Li H, He X, Wang K, Hu J, Tan W, et al. Preparation and antibacterial activity of $\mathrm{Fe}_{3} \mathrm{O}_{4} @ \mathrm{Ag}$ nanoparticles. Nanotechnol. 2007; 18:604-11.

[2] Li WR, Xie XB, Shi QS, Duan SS, Ouyang YS, Chen YB. Antibacterial effect of silver nanoparticles on Staphylococcus aureus. Biometals. 2011; 24:135-41.

[3] Nakonieczna J, Zdonczyk AR, Kawiak A, Bielawskia KP, Grinholc M. Sub-lethal photodynamic inactivation renders Staphylococcus aureus susceptible to silver nanoparticles. Photochem Photobiol Sci. 2013; 12:1622-7. 
[4] Navarro E, Piccapietra F, Wagner B, Marconi F, Kaegi R, Odzak N, et al. Toxicity of silver nanoparticles to Chlamydomonas reinhardtii. Environ Sci Technol. 2008; 42:8959-64.

[5] Panacek A, Kvítek L, Prucek R, Kolar M, Vecerova R, Pizúrova N, et al. Silver colloid nanoparticles: synthesis, characterization, and their antibacterial activity. J Phys Chem B. 2006; 110:16248-53.

[6] Tenover FC. Mechanisms of antimicrobial resistance in bacteria. Am J Med. 2006; 119:3-10.

[7] Rai M, Yadav A, Gade A. Silver nanoparticles as a new generation of antimicrobials. Biotechnol Adv. 2009; 27:76-83.

[8] Guzman M, Dille J, Godet S. Synthesis and antibacterial activity of silver nanoparticles against gram-positive and gram-negative bacteria. Nanomedicine. 2012; 8:37-45.

[9] Feng QL, Wu J, Chen GQ, Cui FZ, Kim TN, Kim JO. A mechanistic study of the antibacterial effect of silver ions on Escherichia coli and Staphylococcus aureus. J Biomed Mater Res. 2000; 52:662-8.

[10] Lok CN, Ho CM, Chen R, He QY, Yu WY, Sun H, et al. Proteomic analysis of the mode of antibacterial action of silver nanoparticles. J Proteome Res. 2006; 5:916-24.

[11] Wigginton NS, de Titta A, Piccapietra F, Dobias J, Nesatyy VJ, Suter MJF, Bernier-Latmani R. Binding of silver nanoparticles to bacterial proteins depends on surface modifications and inhibits enzymatic activity. Environ Sci Technol 2010; 44:2163-8.

[12] Ivask A, ElBadawy A, Kaweeteerawat C, Boren D, Fischer H, Ji Z, et al. Toxicity mechanisms in Escherichia coli vary for silver nanoparticles and differ from ionic silver. ACS Nano. 2014; 8:374-86.

[13] He T, Liu H, Zhou Y, Yang J, Cheng X, Shi H. Antibacterial effect and proteomic analysis of graphene-based silver nanoparticles on a pathogenic bacterium Pseudomonas aeruginosa. Biometals. 2014; 27:673-82.

[14] Mirzajani F, Askari H, Hamzelou S, Schober Y, Römpp A Ghassempour A, Spengler B. Proteomics study of silver nanoparticles toxicity on Bacillus thuringiensis. Ecotoxicol Environ Saf. 2014; 100:122-30.

[15] Gambino M, Marzano V, Villa F, Vitali A, Vannini C, Landini P, Cappitelli F. Effects of sublethal doses of silver nanoparticles on Bacillus subtilis planktonic and sessile cells. J Appl Microbiol. 2015; 118:1103-15.

[16] Qian H, Zhu K, Lu H, Lavoie M, Chen S, Zhou Z, et al. Contrasting silver nanoparticle toxicity and detoxification strategies in Microcystis aeruginosa and Chlorella vulgaris: New insights from proteomic and physiological analyses. Sci Total Environ. 2016; 572:1213-21.

[17] Zheng X, Wang J, Chen Y, Wei Y. Comprehensive analysis of transcriptional and proteomic profiling reveals silver nanoparticlesinduced toxicity to bacterial denitrification. J Hazard Mater. 2018; 344:291-8.

[18] Gong X, Han, L, Gao J, Gao C. Stability of polyelectrolyte multilayer micropatterns in response to post-treatments. Colloids Surf A: Physicochem Eng Aspects. 2012; 396:299-304.

[19] Tamiyakul H, Tanasupawat S, Dubas ST, Warisnoicharoen W. Antibacterial potential of silver nanoparticles capped with poly (4-styrenesulfonic acid-co-maleic acid) polymer. Adv Mat Res. 2015; 1088:64-8.

[20] Lowry OH, Rosebrough NJ, Farr AL, Randall RJ. Protein measurement with the Folin phenol reagent. J Biol Chem. 1951; 193:265-75.

[21] Laemmli UK. Cleavage of structural proteins during the assembly of the head of bacteriophage T4. Nature. 1970; 227:680-5.
[22] Jaresitthikunchai J, Phaonakrop N, Roytrakul S, Veeranondha S, San-ngam R, Suvannapruk W, et al. Protein expression of osteoblast as a response to different hydroxyapatite bioceramics. Proceedings of 48th Kasetsart University Annual Conference: Science. 2010 [cited 2014 June 15], Available from: http://kucon.lib.ku.ac.th/ Fulltext/KC4805022.pdf.

[23] Johansson C, Samskog J, Sundstrom L, Wadensten H, Bjorkesten L, Flensburg J. Differential expression analysis of Escherichia coli proteins using a novel software for relative quantitation of LCMS/MS data. Proteomics. 2016; 6:4475-85.

[24] Thorsell A, Portelius E, Blennow K, Brinkmalm AW. Evaluation of sample fractionation using microscale liquid-phase isoelectric focusing on mass spectrometric identification and quantitation of proteins in a SILAC experiment. Rapid Commun Mass Spectrom. 2007; 21:771-8.

[25] Perkins DN, Pappin DJC, Creasy DM, Cottrell JS. Probability-based protein identification by searching sequence databases using mass spectrometry data. Electrophoresis. 1999; 20:3551-67.

[26] Klinbunga S, Petkorn S, Kittisenachai S, Phaonakrop N, Roytrakul S, Khamnamtong B, Menasveta P. Identification of reproductionrelated proteins and characterization of proteasome alpha 3 and proteasome beta $6 \mathrm{cDNAs}$ in testes of the giant tiger shrimp Penaeus monodon. Mol Cell Endocrinol. 2012; 355:143-52.

[27] Li QW, Lu XY, You Y, Sun H, Liu XY, Ai JZ, et al. Comparative proteomic analysis suggests that mitochondria are involved in autosomal recessive polycystic kidney disease. Proteomics. 2012; 12:2556-70.

[28] Sondi I, Salopek-Sondi B. Silver nanoparticles as antimicrobial agent: A case study on E. coli as a model for Gram-negative bacteria. J Colloid Interface Sci. 2004; 275:177-82.

[29] Morones JR, Elechiguerra JL, Camacho A, Holt K, Kouri JB, Ramírez JT, Yacaman MJ. The bactericidal effect of silver nanoparticles. Nanotechnol. 2005; 16:2346-53.

[30] Kumar GB, Black PN. Bacterial long-chain fatty acid transport: Identification of amino acid residues within the outer membrane protein FadL required for activity. J Biol Chem. 1993; 268:15469-76.

[31] Li WR, Xie XB, Shi QS, Zeng HY, Yang YSO, Chen YB. Antibacterial activity and mechanism of silver nanoparticles on Escherichia coli. Appl Microbiol Biotechnol. 2010; 85:1115- 22.

[32] Jung WK, Koo HC, Kim KW, Shin S, Kim SH, Park YH. Antibacterial activity and mechanism of action of the silver ion in Staphylococcus aureus and Escherichia coli. Appl Environ Microbiol. 2008; 74:2171-8.

[33] Belunis CJ, Raetz CR. Biosynthesis of endotoxins. Purification and catalytic properties of 3-deoxy-D-manno-octulosonic acid transferase from Escherichia coli. J Biol Chem. 1992; 267:9988-97.

[34] Brabetz W, Lindner B, Brade H. Comparative analyses of secondary gene products of 3-deoxy-D-manno-oct-2-ulosonic acid transferases from Chlamydiaceae in Escherichia coli K-12. Eur J Biochem. 2000; 267:5458-65.

[35] Poole K. Bacterial stress responses as determinants of antimicrobial resistance. J Antimicrob Chemother. 2012; 67:2069-89.

[36] Ceciliani F, Caramori T, Ronchi S, Tedeschi G, Mortarino M, Galizzi A. Cloning, overexpression, and purification of Escherichia coli quinolinate synthetase. Protein Expres Purif. 2000; 18: 64-70.

[37] de Ollagnier CS, Loiseau L, Sanakis Y, Barras F, Fontecave M. Quinolinate synthetase, an iron-sulfur enzyme in NAD biosynthesis. FEBS Lett. 2005; 579:3737-43. 
[38] Cicchillo RM, Tu L, Stromberg JA, Hoffart LM, Krebs C, Booker SJ. Escherichia coli quinolinate synthetase does indeed harbor a [4Fe-4S] cluster. J Am Chem Soc. 2005; 127:7310-1.

[39] Gardner PR, Fridovich I. Quinolinate synthetase: The oxygensensitive site of de novo NAD(P)+ biosynthesis. 1991 Arch Biochem Biophys. 1991; 284:106-11.

[40] Batchelor-McAuley C, Tschulik K, Neumann CCM, Laborda E, Compton RG. Why are silver nanoparticles more toxic than bulk silver? towards understanding the dissolution and toxicity of silver nanoparticles. Int. J Electrochem Sci. 2014; 9: $1132-8$.

[41] Lacey MM, Partridge JD, Green J. Escherichia coli K-12 YfgF is an anaerobic cyclic di-GMP phosphodiesterase with roles in cell surface remodelling and the oxidative stress response. Microbiol. $2010 ; 156: 2876-86$.
[42] Bettenbrock K, Bai H, Ederer M, Green J, Hellingwerf KJ, Holcombe M, et al. Towards a systems level understanding of the oxygen response of Escherichia coli. In: Poole RK, editor. Advances in microbial physiology: Advances in microbial systems biology. Vol. 64. London: Academic Press; 2014, pp. 65-114.

[43] Koonin EV. Escherichia coli dinG gene encodes a putative DNA helicase related to a group of eukaryotic helicases including Rad3 protein. Nucleic Acids Res. 1993; 21:1497.

[44] Freedman LP, Zengel JM, Archer RH, Lindahl L. Autogenous control of the S10 ribosomal protein operon of Escherichia coli: genetic dissection of transcriptional and posttranscriptional regulation. Proc Natl Acad Sci USA. 1987; 84:6516-20.

[45] Lange PF, Huesgen PF, Overall CM. TopFIND 2.0-linking protein termini with proteolytic processing and modifications altering protein function. Nucl Acids Res. 2012; 40:351-61. 